\title{
Poly(methyl methacrylate) Supported Pyrazolinium Permanganate: A New Oxidizing Reagent
}

\author{
Shiney Abraham, Padinjare Kochampilly Rajan, and Krishnapillai SReeKumaR ${ }^{\dagger}$ \\ Department of Chemistry, University of Kerala, Kariavattom, Trivandrum-695 581 India
}

(Received March 5, 1996)

\begin{abstract}
Crosslinked polymer-supported analogue of pyrazolinium permanganate was prepared and developed as new recyclable solid-phase oxidizing reagents. The preparation of this new reagent involved a four step polymer analogous reaction starting from divinyl benzene (DVB), ethyleneglycol dimethacrylate (EGDMA), and $N, N^{\prime}$-methylene-bis-acrylamide (N,N'MBA) crosslinked poly(methyl methacrylate) (PMMA). (N,N'MBA crosslinked reagent was found to be efficient in terms of functional group capacity, reaction time, and product yield. This reagent oxidized primary and secondary alcohols to the corresponding carbonyl compounds in high yields. The spent polymeric reagent after oxidation can be easily removed by filtration and be regenerated many times by treating with $\mathrm{KMnO}_{4}$ without loss of capacity.
\end{abstract}

KEY WORDS Pyrazolinium Permanganate / Polymeric Reagent / Solid Phase Organic Synthesis /

Polymer supported solid phase organic synthesis utilizes reactive residues attached to insoluble crosslinked polymeric supports as reagents for effecting functional group conversions. The field of immobilizing chemical reagents on crosslinked polymer supports has received wide application in recent years ${ }^{1-5}$ after the introduction of the solid-phase peptide synthesis by Merrifield. ${ }^{6}$ These immobilized reagents are similar in behavior to low molecular weight analogues but have the inherent advantage of insolubility. It has been established that the nature of the polymeric support matrix has a significant role in swelling and the course of reactions with the soluble substrate. ${ }^{2,7-10}$

\section{EXPERIMENTAL}

The monomers were purified by low pressure distillation. Commercially available low molecular compounds were purified by distillation or recrystallization unless otherwise stated. Microanalyses were done at Regional Sophisticated Instrumentation Centre, IIT, Madras and Central Drug Research Institute, Lucknow. Spectrophotometric measurements were done on Milton and Roy Spectronic 2ID Spectrophotometer. IR spectra were recorded on a Perkin Elmer 397 Spectrometer using $\mathrm{KBr}$ pellets. The copolymers of methyl methacrylate with divinyle benzene (DVB) and ethyleneglycol dimethacrylate (EGDMA) were prepared by suspension polymerization $^{11}$ and with $N, N^{\prime}$-methylene-bis-acrylamide (N,N'MBA) by solution polymerization.

\section{Preparation of Poly(methyl methacrylate) Bound 1,3- Diketone}

The poly(methyl methacrylate) (PMMA) resin (10 g), preswollen in acetonitrile $(20 \mathrm{ml})$, was heated with acetophenone $(20 \mathrm{ml})$ and sodium ethoxide $(5 \mathrm{~g})$ at the refluxing temperature for $12 \mathrm{~h}$. The reaction mixture was then cooled in an ice bath acidified with sulfuric acid $(2 \mathrm{M}, 20 \mathrm{ml})$ solution. The product resin was collected by filtration, washed with water, ethanol, and acetone $(20 \mathrm{ml} \times 3$ times each), and dried in vacuum to constant

\footnotetext{
† To whom correspondence should be addressed.
}

weight. Yield, $10.8 \mathrm{~g}, 11.1 \mathrm{~g}, 11.3 \mathrm{~g}$, respectively for DVB, EGDMA, and N, N'MBA crosslinked resins.

Estimation of Enolic (-OH) Capacity of 1,3-Diketo Resins The 1,3-diketo resin $(200 \mathrm{mg})$ was mixed with acetylating mixture $(10 \mathrm{ml})$ and stirred for $10 \mathrm{~h}$. Water $(10 \mathrm{ml})$ was added and stirred for another $1 \mathrm{~h}$. The liberated acetic acid was then titrated against alcoholic $\mathrm{KOH}(0.5 \mathrm{~N})$ using phenolphthalein as indicator. A blank was also conducted. From the titer values, enolic capacity was determined.

Capacity: 2.6, 2.8, and $3.0 \mathrm{meq} / \mathrm{g}$, respectively for DVB, EGDMA, and N,N'MBA crosslinked PMMA supported resins.

\section{Preparation of PMMA Bound Pyrazole}

PMMA supported 1,3-diketone ( $10 \mathrm{~g})$ preswollen in acetonitrile $(20 \mathrm{ml})$ was stirred with hydrazine sulphate $(10 \mathrm{~g})$ in the presence of pyridine $(10 \mathrm{ml})$ at room temperature for $12 \mathrm{~h}$. The reaction mixture was cooled and the resin particles were collected by filtration at the pump. The resin was washed successively with acetonitrile, dioxane-water $(1: 1)$ ethanol, methanol, and dried in vacuum to constant weight. Yield, $10.6 \mathrm{~g}, 10.7 \mathrm{~g}$, $10.5 \mathrm{~g}$, respectively for DVB, EGDMA, and N,N'MBA crosslinked resins.

\section{Estimation of Nitrogen in the Resins}

The pyrazole resin $(100 \mathrm{mg})$ was mixed with $\mathrm{K}_{2} \mathrm{SO}_{4}$ $\mathrm{CuSO}_{4}-\mathrm{HgO}$ mixture in $15: 2: 1$ ratio $(0.7 \mathrm{~g})$ in a Kjeldahl's flask and digested for $4 \mathrm{~h}$ after addition of concn $\mathrm{H}_{2} \mathrm{SO}_{4}(2 \mathrm{ml})$. When the solution attained a blue color and was clear, it was transferred quantitatively into an ammonia distillation unit. Sodium hydroxide solution $(60 \%, 10 \mathrm{ml})$ and a pellet of sodium thiosulphate were added to the solution. A stream of steam was passed through the solution and the liberated ammonia was collected in a saturated boric acid solution $(20 \mathrm{ml})$. It was then titrated against $\mathrm{HCl}(0.1 N)$ using methylene blue-methyl red indicator till the color of the solution changed from green to blue. From the titer values, the percentage of nitrogen in the resin was estimated.

$\% \mathrm{~N}: \quad 6.8,7.0$, and 7.5 , respectively for DVB, 
EGDMA, and N,N'MBA crosslinked PMMA supported resins.

\section{Quaternization of Polymeric Pyrazole Resins}

Polymeric pyrazole resin $(10 \mathrm{~g})$ preswollen in acetonitrile $(20 \mathrm{ml})$ was reacted with methyl iodide $(10 \mathrm{ml})$ at the refluxing temperature for $10 \mathrm{~h}$. After the reaction, the mixture was filtered, washed with water, ethanol, and acetone $(20 \mathrm{ml} \times 3)$, dried and weighed. Yield $9.7 \mathrm{~g}, 9.9 \mathrm{~g}$, $10.0 \mathrm{~g}$, respectively for DVB, EGDMA, and N,N'MBA crosslinked resins.

\section{Estimation of Iodide in Pyrazolinium Iodide Resin}

A definite amount $(0.5 \mathrm{~g})$ of quaternized resin preswollen in acetone $(10 \mathrm{ml})$ was allowed to react with silver nitrate $(20 \mathrm{ml})$ for $5 \mathrm{~h}$. The excess silver nitrate was then titrated against standard ammonium thiocyanate solution $(0.1 \mathrm{~N})$ using ferric alum as indicator till a reddish brown color developed. A blank experiment was also conducted. From the two titer values, iodide ion content in the resins was determined.

Capacity: $16.0,2.0$, and $2.1 \mathrm{meq} \mathrm{g}^{-1}$, respectively for DVB, EGDMA, and N,N'MBA crosslinked resins.

\section{Preparation of Polymeric Pyrazolinium Permanganate Resin}

Quaternized polymeric pyrazole resin $(10 \mathrm{~g})$ was reacted with potassium permanganate $(2 \mathrm{~g})$ in acetonewater mixture $(2: 1 \mathrm{v} / \mathrm{v}, 25 \mathrm{ml})$ at $0^{\circ} \mathrm{C}$ for $4 \mathrm{~h}$. After the reaction, the mixture was filtered, washed with water, ethanol, and acetone $(20 \mathrm{ml} \times 3$ times each $)$, dried and weighed. Yield, $9.8 \mathrm{~g}, 9.9 \mathrm{~g}, 10.1 \mathrm{~g}$, respectively for DVB, EGDMA, and N,N'MBA crosslinked resins.

\section{Estimation of Permanganate in the Pyrazolinium Per- manganate Resin}

The permanganate resin $(0.5 \mathrm{~g})$ was suspended in $\mathrm{H}_{2} \mathrm{SO}_{4}(2 \mathrm{~N}, 30 \mathrm{ml})$ containing acetone $(10 \mathrm{ml})$. The resin was allowed to swell in the medium for about $1 \mathrm{~h}$. Ferrous ammonium sulphate solution $(20 \mathrm{ml})$ was added and stirred until the dark color of the resin completely disappeared and turned almost white. The unreacted ferrous ammonium sulphate solution was titrated against standard $\mathrm{KMnO}_{4}$ solution. From the titer values, permanganate capacity was calculated.

Capacity: $1.2,1.5$, and $1.7 \mathrm{mmol} \mathrm{g}^{-1}$, respectively for DVB, EGDMA, and N,N'MBA crosslinked resins.

\section{Oxidation Reaction Using PMMA Based Pyrazolinium Permanganate Resin}

The alcohol $(1 \mathrm{mmol})$ was dissolved in chloroform $(10 \mathrm{ml})$. Two-fold molar excess of the polymeric reagent was added and the reaction mixture was stirred. The reaction was followed by thin layer chromatography. After completion of the reaction, the resin was filtered and washed with chloroform. The combined filtrate and washings on evaporation of the solvent afforded the corresponding carbonyl compounds. The products were identified and characterized by comparison $(\mathrm{mp} / \mathrm{bp}$ and IR) with authentic samples.

\section{Recycling of PMMA Bound Pyrazolinium Permanganate Resin}

The spent polymeric reagent $(5 \mathrm{~g})$ collected from different experiments was stirred for $2 \mathrm{~h}$ with $2 \mathrm{~N}$ solution $(50 \mathrm{ml})$ of ferrous ammonium sulphate in the presence of $2 \mathrm{~N} \mathrm{H}_{2} \mathrm{SO}_{4}(20 \mathrm{ml})$ to remove all oxides of manganese. The resin was filtered, washed with water, and dried. The regenerated polymer was functionalized with permanganate as described earlier.

\section{RESULTS AND DISCUSSION}

\section{Preparation and Characterization of PMMA Bound Pyrazolinium Permanganate Resins}

The solid phase analogue of pyrazolinium permanganate was prepared by a four-step polymer analogous reaction starting from DVB, EGDMA, and N,N'MBA crosslinked PMMA resins (Scheme 1). The degree of crosslinking of the three resins was fixed at $2 \%$. The resins were microporous or gels and had a particle size of 200-400 mesh. The IR spectra of DVB crosslinked PMMA resin showed an absorption band at $1735 \mathrm{~cm}^{-1}$ $\left(\mathrm{C}=\mathrm{O}\right.$ str ester). The appearance of peaks at $1580 \mathrm{~cm}^{-1}$ (C-C arom str) and $3030 \mathrm{~cm}^{-1}(\mathrm{C}-\mathrm{H} \mathrm{str})$ indicates the incorporation of DVB residue in the polymer. EGDMA crosslinked PMMA resin showed peaks at $1735 \mathrm{~cm}^{-1}$ $\left(\mathrm{C}=\mathrm{O}\right.$ str ester of MMA) and $1740 \mathrm{~cm}^{-1}(\mathrm{C}=\mathrm{O}$ str ester of EGDMA). The spectra of N,N'MBA crosslinked resin showed IR bands at $1730 \mathrm{~cm}^{-1}(\mathrm{C}=\mathrm{O} \mathrm{str}) 1120 \mathrm{~cm}^{-1}$ (C-O str) of methyl ester and $1690 \mathrm{~cm}^{-1}(\mathrm{C}=\mathrm{O} \mathrm{str})$, $3400 \mathrm{~cm}^{-1}$ (N-H str) of amide group. The PMMA resin (1a, 1b, 1c) was converted to the $\beta$-diketo resin $(\mathbf{2 a}, \mathbf{2 b}$, 2c) by Claisen condensation reaction with acetophenone and sodium ethoxide. The $\beta$-diketo resin was a tautomeric product as evident from the IR spectral values. Observed - $\mathrm{OH}$ stretching frequencies were low and the IR spectra showed enol absorption band at $2900 \mathrm{~cm}^{-1}$. The absorption band at $1670-1680 \mathrm{~cm}^{-1}$ was assigned to $\mathrm{C}=\mathrm{O} \cdots \mathrm{H}$ and $\mathrm{C}=\mathrm{C}$ stretching vibrations characteristic of cyclic intramolecular hydrogen bonded molecules. Absorption bands at $1700-1740 \mathrm{~cm}^{-1}$ were assigned to two $\mathrm{C}=\mathrm{C}$ stretching vibrations of the keto form. Enol capacity was determined by acetylation ${ }^{12}$ as 60,68 , and $70 \%$ respectively for resins $\mathbf{2 a}, \mathbf{2} \mathbf{b}$, and $\mathbf{2 c}$. The $\beta$-diketo resin was then converted to the pyrazole functionalized resin by treatment with hydrazine sulphate in pyridine. The formation of pyrazole resin $(\mathbf{3 a}, \mathbf{3 b}, \mathbf{3} \mathbf{c})$ was supported by nitrogen estimation and the occurrence of strong bands at $1620 \mathrm{~cm}^{-1}(\mathrm{C}=\mathrm{N}$ str $), 1300 \mathrm{~cm}^{-1}(\mathrm{C}-\mathrm{N}$ str), and $1650 \mathrm{~cm}^{-1}(\mathrm{C}=\mathrm{C}$ str $)$. The pyrazole resin was then quaternized with $\mathrm{CH}_{3} \mathrm{I}$ in acetonitrile as the solvent. The quaternized resin $(\mathbf{4 a}, \mathbf{4 b}, \mathbf{4 c})$ was characterized by IR absorption bands at $2900 \mathrm{~cm}^{-1}\left(\mathrm{~N}-\mathrm{CH}_{3} \mathrm{str}\right)$. The capacity of $\mathrm{I}^{-}$was estimated by treatment of the resins with $\mathrm{AgNO}_{3}$ followed by determination of displaced iodide as silver iodide. Capacity was 1.6, 2.0, and $2.1 \mathrm{meqg}^{-1}$, respectively for DVB, EGDMA, and N, N'MBA crosslinked resins. Permanganate ions were introduced into the resin by replacing $\mathrm{I}^{-}$by $\mathrm{MnO}_{4}^{-}$using an aqueous solution of $\mathrm{KMnO}_{4}$ in acetone. The permanganate resin $(\mathbf{5 a}, \mathbf{5 b}, \mathbf{5 c})$ was characterized by IR absorption bands at $900 \mathrm{~cm}^{-1}$ due to $\mathrm{MnO}_{4}^{-}$stretching. Permanganate capacity was determined by treatment of 
the resin with excess standard ferrous ammonium sulphate solution and the unreacted ferrous ammonium sulphate solution was titrated against a standard solution of $\mathrm{KMnO}_{4}$. Capacity was $1.2,1.5$, and $1.7 \mathrm{mmol} \mathrm{g}^{-1}$, respectively for resin $\mathbf{5 a}, \mathbf{5 b}$, and $\mathbf{5 c}$. Some functional groups may possibly remain unreacted during functional group conversion. To avoid this, all steps of the reaction were repeated twice or thrice so that maximum conversion was achieved in all cases. This ensured participation of all functional groups at every step of the reaction. Thus, the product polymer obtained after each reaction is considered to be pure and no residual functional groups are detected chemically or spectroscopically.

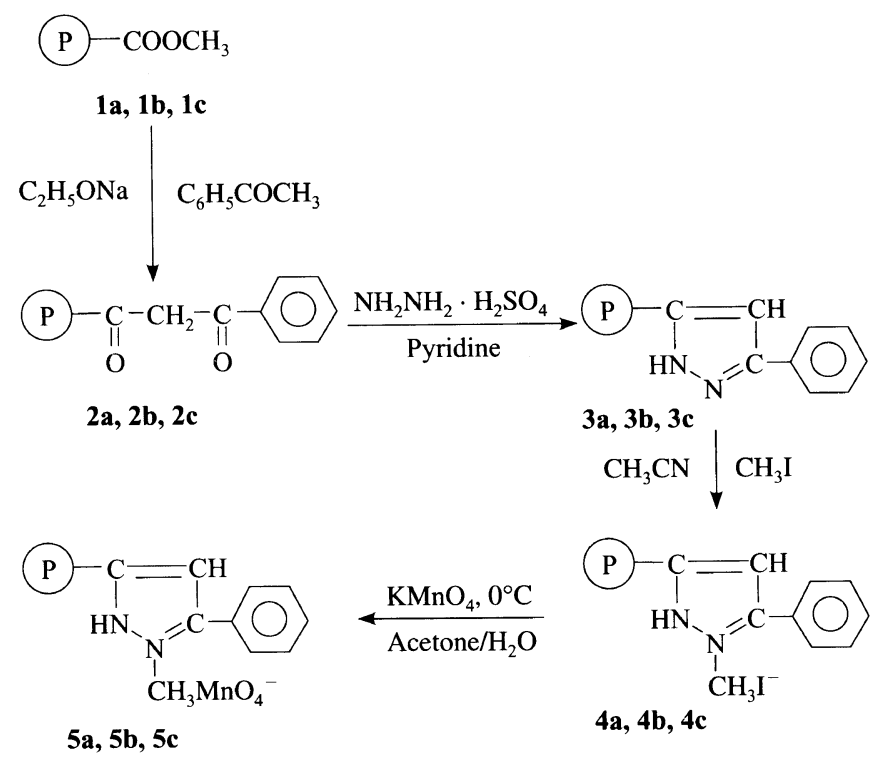

Scheme 1. Synthesis of poly(methyl methacrylate)-supported pyrazolinium permanganate resin.

Of the three systems, EGDMA and N,N'MBA crosslinked resins have higher capacity. The $\mathrm{N}, \mathrm{N}^{\prime} \mathrm{MBA}$ crosslinked resin possess the highest reactivity towards functionalization. The reagent prepared from $\mathrm{N}, \mathrm{N}^{\prime} \mathrm{MBA}$ crosslinked resin was more reactive. This could be attributed to the better hydrophilic/hydrophobic balance in this system due to the presence of more flexible N,N'MBA crosslinkage.

\section{Oxidation of Alcohols Using Polymer Bound Pyrazolinium Permanganate Resins}

The pyrazolinium permanganate resin was observed to be capable of oxidizing primary and secondary alcohols to the corresponding carbonyl compounds. Oxidation conditions involved stirring of the alcohol with 2-fold molar excess pyrazolinium permanganate functions in the resin in solvents like chloroform or methylene chloride at $30^{\circ} \mathrm{C}$. The workup of the reaction mixture involved filtration of the spent residue, washing and removal of the solvent from the combined filtrate and washings to afford the oxidized product. Difierent alcohols which were oxidized using this procedure, the yield and conditions of oxidation are presented in Table I.

Dependence of the structure of the alcohol on reaction time and product yield was also a notable factor. Thus, $\alpha$-phenylethanol took $27 \mathrm{~h}$ for $81 \%$ conversion while $p$-methoxy $\alpha$-phenylethanol needed only $25 \mathrm{~h}$ for $85 \%$ conversion using DVB crosslinked PMMA supported reagent. This effect of the structure of alcohol on the oxidation reaction could be seen in benzyl alcohol and substituted benzyl alcohols also. Benzyl alcohol gave $82 \%$ benzaldehyde within $28 \mathrm{~h}$, while $p$-methylbenzyl alcohol needed only $25 \mathrm{~h}$ for $83 \%$ conversion, in the case of DVB-crosslinked PMMA supported permanganate resins.

Oxidation with this polymer supported permanganate reagent shows some distinct differences from the oxidation with $\mathrm{KMnO}_{4}$. The oxidation of alcohols with $\mathrm{KMnO}_{4}$ generally yields the corresponding acids through the intermediate carbonyl compound. But in the case of polymer-supported permanganate, the oxidation stops at the carbonyl stage even with excess of the polymer supported permanganate and extended duration of the reaction. This can be assumed as the effect of the crosslinked polymer matrix. A similar observation of the absence of any acids as products in the oxidation of alcohols has been made in the case of oxidations using other polymer supported permanganate reagents. ${ }^{13-15}$ This polymer-supported permanganate is unique in that it can bring about the oxidation of alcohol group directly attached to the ring structure unlike in the case of poly(4-vinyl pyridinium) permanganate ${ }^{13)}$ reagent. The time required for complete oxidation in the case of the present permanganate reagent was found to be much

Table I. Oxidation reactions using PMMA-supported pyrazolinium permanganate resin

\begin{tabular}{|c|c|c|c|c|c|c|c|c|}
\hline \multirow{2}{*}{ Alcohol $^{\mathrm{a}}$} & \multicolumn{3}{|c|}{ Time/h } & \multirow{2}{*}{ Product $^{b}$} & \multicolumn{3}{|c|}{ Isolated yield $/ \%$} & \multirow{2}{*}{$\mathrm{mp}(\mathrm{bp})$} \\
\hline & $5 \mathbf{a}$ & $5 \mathbf{b}$ & $5 c$ & & $\mathbf{5 a}$ & $\mathbf{5 b}$ & $5 c$ & \\
\hline Benzoin & 20 & 18 & 17 & Benzil & 86 & 88 & 89 & 95 \\
\hline Benzhydrol & 22 & 20 & 18 & Benzophenone & 84 & 85 & 88 & 49 \\
\hline Benzyl alcohol & 28 & 26 & 24 & Benzaldehyde & 82 & 83 & 86 & $(176)$ \\
\hline$n$-Butanol & 26 & 24 & 22 & $n$-Butyraldehyde & 80 & 81 & 84 & $(75)$ \\
\hline$p$-Nitrobenzyl alcohol & 30 & 28 & 26 & $p$-Nitrobenzaldehyde & 80 & 80 & 83 & 58 \\
\hline$\alpha$-Phenylethanol & 27 & 25 & 23 & Acetophenone & 81 & 82 & 85 & $(202)$ \\
\hline p-Methylbenzyl alcohol & 25 & 23 & 21 & $p$-Methylbenzaldehyde & 83 & 84 & 86 & (205) \\
\hline cis-1,2-Cyclohexane diol & 22 & 19 & 19 & 2-Hydroxycyclohexanone & 84 & 84 & 85 & 105 \\
\hline$p$-Methoxy- $\alpha$-phenylethanol & 25 & 23 & 21 & $p$-Methoxyacetophenone & 85 & 86 & 90 & 39 \\
\hline
\end{tabular}

${ }^{a}$ Solvent, chloroform; temperature, $30^{\circ} \mathrm{C}$; resin to alcohol ratio, $2: 1 .{ }^{b}$ Products characterized by comparison with authentic samples (IR and $\mathrm{mp} / \mathrm{bp})$. 
shorter compared to the other polymeric reagents. Also the reactions were generally carried out at room temperature in the present case contrary to a high temperature $\left(70^{\circ} \mathrm{C}\right)$ reaction in the other cases.

\section{Comparison with Low Molecular Weight Reagent}

Unsupported pyrazolinium permanganate was prepared starting from 1-benzoyl acetone, which has an enol content of $99 \%{ }^{16)}$ Benzoyl acetone was converted to 3(5)-methyl phenyl pyrazole by treatment with hydrazine sulphate. The formation of the pyrazole was supported by nitrogen estimation ( $\% \mathrm{~N}=17.7 \%)$ and IR bands at $1620 \mathrm{~cm}^{-1}(\mathrm{C}=\mathrm{N}$ str $), 1300 \mathrm{~cm}^{-1}(\mathrm{C}=\mathrm{N}$ str $)$, and $1650 \mathrm{~cm}^{-1}$ ( $\left.\mathrm{C}=\mathrm{C} \mathrm{str}\right)$. The pyrazole was converted to pyrazolinium iodide using methyl iodide. It was characterized by absorption band at $2900 \mathrm{~cm}^{-1}\left(\mathrm{~N}-\mathrm{CH}_{3}\right.$, str) in IR spectrum. $\mathrm{I}^{-}$capacity was $3.3 \mathrm{meq}^{-1}$. Finally, pyrazolinium permanganate was prepared by reaction of pyrazolinium iodide with $\mathrm{KMnO}_{4}$ in acetone and the product formed was extracted using ether after evaporating excess acetone. The pyrazolinium permanganate was totally insoluble in nonpolar solvents such as chloroform, dichloromethane, benzene, and cyclohexane, and soluble in polar solvents like ether, dioxan, tetrahydrofuran, and acetonitrile. Permanganate capacity was $3.4 \mathrm{mmol} \mathrm{g}^{-1}$. The reagent oxidized primary alcohols to acids and secondary alcohols to ketones. The reaction took place only in the presence of a trace amount of water making the separation of the products difficult. Reaction cannot be stopped at the stage of aldehyde in the case of oxidation of primary alcohols. The reaction was so rapid that at the very start of the reaction, both aldehyde and acid were produced. Thus the oxidation of primary alcohols like benzyl alchool and $n$-butanol resulted in the formation of two products (the aldehyde and acid, identified by (TLC) just after 30 min of reaction. At that time, considerable starting material remained unreacted. By $2 \mathrm{~h}$, almost complete reaction was possible, but both aldehyde and acid were still present, the acid product in slightly higher amount. On prolonged reaction, complete conversion of aldehyde to acid did not take place. The oxidation of secondary alcohols did not pose such problems; the only products obtained were the corresponding ketones.

\section{Effects of Reaction Conditions on the Extent of Oxidation}

The oxidation reaction using pyrazolinium permanganate resin was affected by the nature of the solvent, temperature, and the effective concentration of the reagent function. Only when there is an effective interaction between the reagent function attached to the macromolecular matrix, the substrate and the reaction medium, reaction takes place with a reasonable extent of functional group conversion.

\section{Effect of Solvents}

Investigation of the effect of solvents on the oxidation of alcohol using PMMA based pyrazolinium permanganate resin revealed that tetrahydrofuran (THF) is the most effective solvent. The oxidation reaction was carried out in solvents of varying polarity. The solvents used were dichloromethane, THF, chloroform, dioxane, benzene, acetonitrile, and cyclohexane. The results are
Table II. Dependence of the oxidation of benzoin on solvent

\begin{tabular}{llcc}
\hline \multirow{2}{*}{ Solvent } & \multicolumn{3}{c}{ Time for complete conversion ${ }^{\mathbf{a}} / \mathrm{h}$} \\
\cline { 2 - 4 } & $\mathbf{5 a}$ & $\mathbf{5 b}$ & $\mathbf{5 c}$ \\
\hline Dichloromethane & 24 & 16 & 16 \\
Tetrahydrofuran & 23 & 16 & 14 \\
Chloroform & 20 & 18 & 17 \\
Dioxan & 24 & 21 & 19 \\
Actonitrile & 18 & 15 & 13 \\
Cyclohexane & 22 & 24 & 24 \\
\hline
\end{tabular}

${ }^{a}$ Resin to alcohol ratio, $2: 1$; temperature, $30^{\circ} \mathrm{C}$.

Table III. Effect of temperature on oxidation reaction

\begin{tabular}{cccc}
\hline & \multicolumn{3}{c}{ Time for maximum conversion ${ }^{\mathrm{a}} / \mathbf{h}$} \\
\cline { 2 - 4 } Temperature $/{ }^{\circ} \mathbf{C}$ & $\mathbf{5 a}$ & $\mathbf{5 b}$ & $\mathbf{5 c}$ \\
\hline 20 & 27 & 25 & 23 \\
30 & 20 & 18 & 17 \\
40 & 17 & 14 & 14 \\
50 & 13 & 11 & 10 \\
60 & 11 & 8 & 7 \\
\hline
\end{tabular}

a Solvent, chloroform; alcohol, benzoin; resin to alcohol ratio, $2: 1$.

Table IV. Effect of molar ratio on the oxidation of benzoin

\begin{tabular}{cccc} 
& \multicolumn{3}{c}{$\%$ Conversion of benzoin after $10 \mathrm{~h}^{\mathrm{a}}$} \\
\cline { 2 - 4 } & $\mathbf{5 a}$ & $\mathbf{5 b}$ & $\mathbf{5 c}$ \\
\hline $1: 1$ & 17 & 20 & 23 \\
$1: 2$ & 28 & 32 & 35 \\
$1: 3$ & 35 & 40 & 43 \\
$1: 4$ & 38 & 44 & 47 \\
$1: 5$ & 44 & 48 & 52 \\
\hline
\end{tabular}

${ }^{a}$ Solvent, chloroform; temperature, $30^{\circ} \mathrm{C}$.

given in Table II.

Polar solvents like THF and acetonitrile have pronounced effect on the extent of oxidation. This is because the introduction of ionic permanganate function into the PMMA matrix introduces more polarity to the network, thus enhancing affinity towards polar solvents.

\section{Effect of Temperature}

To study the effect of temperature on the reactivity of PMMA-supported pyrazolinium permanganate resin, the oxidation of alcohol was conducted at various temperatures in chloroform as the solvent. The time for maximum conversion was determined. The results are presented in Table III. As the temperature was raised, time for maximum conversion decreased.

\section{Effect of Molar Ratio}

Oxidation of benzoin was carried out by varying the molar excess of PMMA-supported pyrazolinium permanganate resins, the other experimental conditions being the same. In the present study, the relative concentrations were $1: 1,2: 1,3: 1,4: 1$, and $5: 1$. When molar equivalents were used, the reaction did not go to completion in any case, irrespective of the duration of the reaction. The results are shown in Table IV. With increase in resin to benzoin ratio, there was correspond- 
Table V. Recycling of pyrazolinium permanganate resin

\begin{tabular}{ccccccccc}
\hline \multirow{2}{*}{$\begin{array}{c}\text { No. of } \\
\text { cycles }\end{array}$} & \multicolumn{3}{c}{ Capacity $/ \mathrm{mmol} \mathrm{g}^{-1}$} & & \multicolumn{3}{c}{ \% Yield } \\
\cline { 7 - 9 } \cline { 6 - 8 } & $\mathbf{5 a}$ & $\mathbf{5 b}$ & $\mathbf{5 c}$ & & $\mathbf{5 a}$ & $\mathbf{5 b}$ & $\mathbf{5 c}$ \\
\hline 1 & 1.2 & 1.5 & 1.7 & & 86 & 88 & 89 \\
2 & 1.2 & 1.4 & 1.6 & & 84 & 84 & 86 \\
3 & 1 & 1.3 & 1.5 & & 83 & 82 & 84 \\
4 & 0.9 & 1.3 & 1.5 & & 82 & 82 & 84 \\
5 & 0.9 & 1.2 & 1.4 & & 82 & 80 & 82 \\
\hline
\end{tabular}

${ }^{a}$ Alcohol, benzoin; solvent, chloroform; temperature, $30^{\circ} \mathrm{C}$; molar

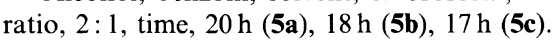

ing increase in percentage yield.

Recycling of the PMMA-Supported Pyrazolinium Permanganate Resin

The polymeric byproduct obtained after the oxidation reaction was found to contain unreacted $\mathrm{MnO}_{4}^{-}$residues which were removed by washing the resin with ferrous ammonium sulphate solution. The regenerated resin was treated with $\mathrm{KMnO}_{4}$ as the original case. The regenerated resin was equally good in oxidizing alcohols. The change in the capacity of the resins in the course of the recycling steps using pyrazolinium permanganate resins is presented in Table V.
Acknowledgement. The authors thank the University Grants Commission, New Delhi for a fellowship to SA.

\section{REFERENCES}

1. N. K. Mathur, C. K. Narang, and R. E. Williams, "Polymers as Aids in Organic Chemistry," Academic Press, New York, N.Y., 1980.

2. P. Hodge and D. C. Sherrington, (Ed)., "Polymer Supported Reactions in Organic Synthesis," Wiley, New York, N.Y., 1980.

3. M. A. Kranus and A. Patchornik, Macromol. Rev., 15, 55 (1980).

4. A. Patchornik, in "Macromolecules," H. Benoit, P. Rempp, Ed., Pergamon Press, Oxford, 1982, p 133.

5. A. Akelah and D. C. Sherrington, Chem. Rev., 81, 557 (1981).

6. R. B. Merrifield, J. Am. Chem. Soc., 85, 2149 (1963).

7. V. Paulette and A. Isabella, J. Chem. Soc., Perkin Trans. 1, 66, 1351 (1984)

8. B. Sket, M. Zupan, and P. Zupet, Tetrahedron, 40, 1606 (1984).

9. J. I. Crowley and H. Rapoport, Acc. Chem. Res., 9, 135 (1976).

10. J. A. Grieg and D. C. Sherrington, Polymer, 19, 163 (1978).

11. D. P. Hart, in "Macromolecular Synthesis," J. A. Moore, Ed., Wiley, New York, N.Y., 1977, Collect Vol. I, p 23.

12. S. Siggia, "Quanititative Organic Analysis via Functional Group,' 2nd ed, John Wiley and Sons Inc., New York, N.Y., 1954, p 10.

13. K. J. John and V. N. R. Pillai, J. Polym. Sci., Part A, Polym. Chem., 27, 2897 (1989).

14. K. J. John, Ph.D. Thesis, M. G. University, Kottayam, 1989.

15. J. Zacharias and V. N. R. Pillai, Abstracts, "National Seminar on New Frontiers in Chemistry," Publication Division, University of Kerala, Trivandrum, 1991, p 37.

16. L. Fieser and M. Fieser, Advanced Organic Chemistry, 409 (1961). 